\title{
Experimental Determination of Impact Strength of Aluminium, Borassus Flabellifer Fiber and Polyester Composites
}

\author{
Mohammed Kareemulla ${ }^{1}$, RameshUddagiri ${ }^{2}$, Sadanandam Pilli ${ }^{3}$ \\ ${ }^{1,2,3}$ Faculty, Department of Mechanical Engineering, Institute of Technology, Dire Dawa University, \\ Dire Dawa, Ethiopia.
}

\begin{abstract}
The usage of natural fibres like borassus flabellifer fiber, flax, sisal, jute, kenaf, etc. as replacement to manmade fibers in fiber-reinforced composites have increased now a days due to advantages like low density, low cost and biodegradability. In addition to this poor compatibility with the matrix and high absorption content of natural fibers, focus is diverted to fiber reinforced composites. In this research, the standard test method of ASTM D256M is used to prepare specimens for testing Impact strength properties of fiber-resin composites. The test specimen has a constant cross section with tabs bonded at the ends. The specimens were incorporated with borassus flabellifer fiber. Five identical specimens were prepared for each weight by varying fiber content in grams i.e. 0.5, 1.0, 1.5, 2.0, 2.5. Impact strength of fabricated composites were calculated.It is found that the Impact strength is increased with increase in weight of fiber. The Impact strength of pure polyester is also determined experimentally. The impact strength of pure polyester is $12.5 \mathrm{~J} / \mathrm{m}$. The Impact strength of fibered composite is $460 \mathrm{~J} / \mathrm{m}$ (for maximum loading fiber)
\end{abstract}

Keywords: Fiber reinforced composites, Natural Composites, Impact Strength.

\section{Introduction}

With the increased trend for sustainable and environmentally friendly materials, polymer composit industries diverted their attention towards bio degradable polymers from renewable resources such as PVA (polyvinyl alcohol).Biopolymers offer environmental benefits such as biodegradability, less greenhouse gas emissions, and renewability of the base material. Bio-composites are usually fabricated with biodegradable/nonbiodegradable polymers as matrix and natural fibers as reinforcement. Many lingo cellulosic fibers, such as jute, hemp, sisal, abaca etc. are used as reinforcement for biodegradable bio-composites because of their good mechanical properties and low specific mass has received much attention for biodegradable polymers. PVA is linear aliphatic thermoplastic polyester, produced from renewable agricultural resources. PVA has properties that are competitive to many commodity polymers (e.g. PP, PE, PLA, PS) such as high stiffness, clarity, gloss, and UV stability. A way to improve the mechanical and thermal properties of PVA is the addition of fibers or filler materials. Combining PVA with natural fibers which are abundantly, readily available such as kenaf, jute, sisal etc. can lead to a totally bio degradable composite made only from renewable resources.

1. Bast or Stem fibres (jute, mesta, banana etc.)

2. Leaf fibres (Palmyra palms, Elephant grass, sisal, pineapple, screw pine etc.)

3. Fruit fibres (cotton, coir, oil palm etc.).

\subsection{Materials:}

\section{Experimental Procedure}

Palmyra palms are economically useful and widely cultivated in tropical regions. The Palmyra palm has long been one of the most important trees of Cambodia and India where it has over 800 uses. The leaves are used for thatching, mats, baskets, fans, hats, umbrellas, and as writing material and PVA (polyvinyl alcohol).

Aluminum

Borassus flabellifer fiber

Polyester

\subsection{Extraction of Fiber}

Fiber is available in the form of bract on a Palmyra tree .First collect and dried bracts from the Palmyra tree then after segregating fibers from the bract, then after Fibers are cleaned and dried under sun for two days to remove moisture content. Further, the fibers were kept in oven for 2 hours at $70^{\circ} \mathrm{C}$ to ensure that maximum moisture was removed. The above fibers extracted by different methods are used for making composite specimens. In this work Palmyra bract fiber $40 \mathrm{~cm}$ long in general is considered. 


\subsection{Composite Fabrication}

The test specimen has a constant cross section with tabs bonded at the ends. The specimen is prepared by hand layup process in the form of a rectangular strip of $65 \times 13 \times 10 \mathrm{~mm}$ thick and ground to conform to the dimensions. The mould is prepared on smooth ceramic tile with rubber shoe sole to the required dimension. Initially the ceramic tile is cleaned with shellac (NC thinner) a spirituous product to ensure clean surface on the tile. Then mould is prepared keeping the rubber sole on the tile. The gap between the rubber and the tile is filled with mansion hygienic wax. A thin coating of PVA (polyvinyl alcohol) is applied on the contact surface of specimen, using a brush. The resulting mould is cured for one hour.

\subsection{Impact Strength Test}

The impact testing equipment compiles with ASTM standards. Depending on the volume fraction of the specimen, one of the four hammers has to be selected to break the sample. The hammer is fixed to the pendulum in such a way that it will make initial contact with the specimen on a line $22 \mathrm{~mm}$ above the top surface of the clamping vice. The sample is fixed to the vice as a vertical cantilever beam in such a way that the notch faces the striking edge of the hammer and aligned with the surface of the vice. The pendulum hammer is released from its locking position which is at an angle of $150^{\circ}$ with respect to the axis of specimen with a striking velocity of $2.46 \mathrm{~m} / \mathrm{sec}$. The sample is stripped and energy is indicated in joules by the pointer on the respective scale. The impact energy is calculated as per the ASTM standards.

\section{Results and Discussion}

The Impact energy of treated and untreated borassus flabellifer fiber /PVA as a function of the borassus flabellifer fiber content is presented in figure 3.1,3.2\&3.3 From figures 3.1,3.2\&3.3 it was observed that the Tensile strength of composite increased with increase in the fibre loading up to 2.5 grams weight and the Modulus is given maximum at 2grams of borassus flabellifer fiber/PVA composites.

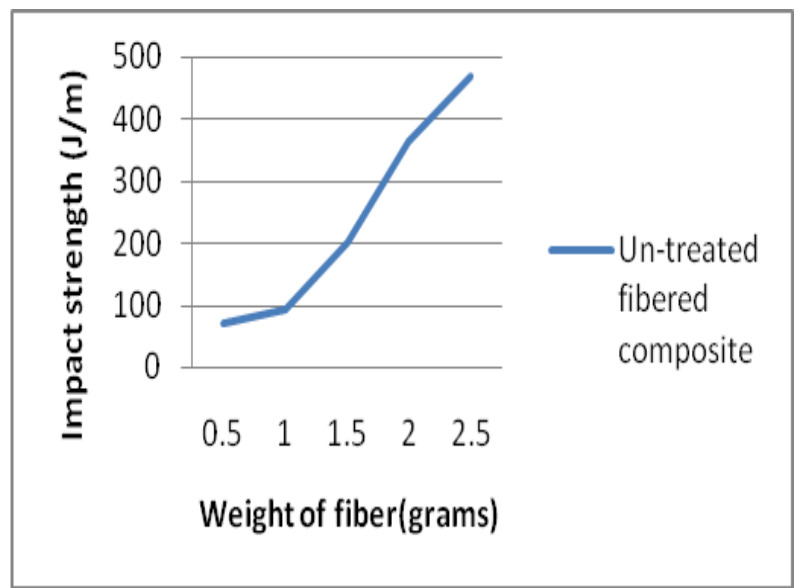

Figure 3.1: Variation of Impact energy of untreated borassus flabellifer fiber /PVA composite with fiber loading.

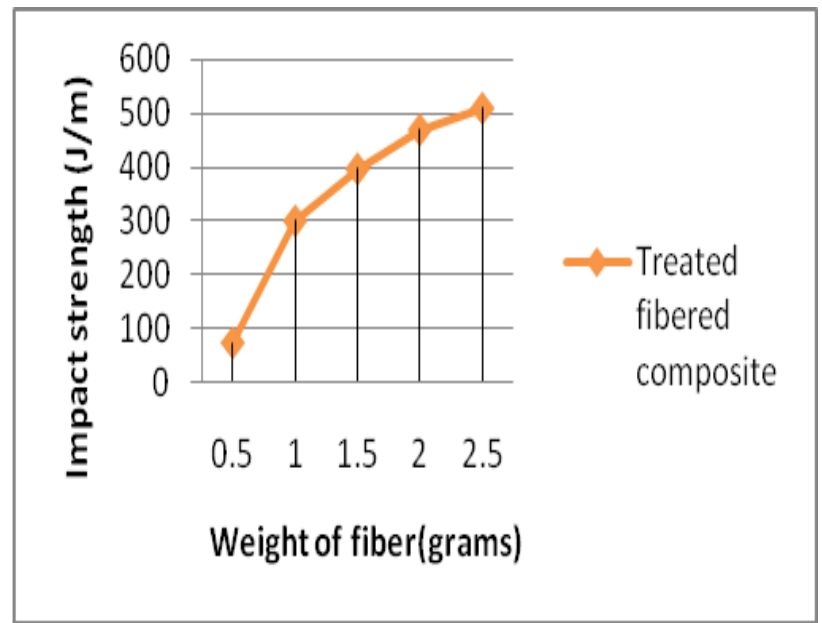

Figure 3.2: Variation of Impact energy of treated borassus flabellifer fiber /PVA composite with fiber loading. 


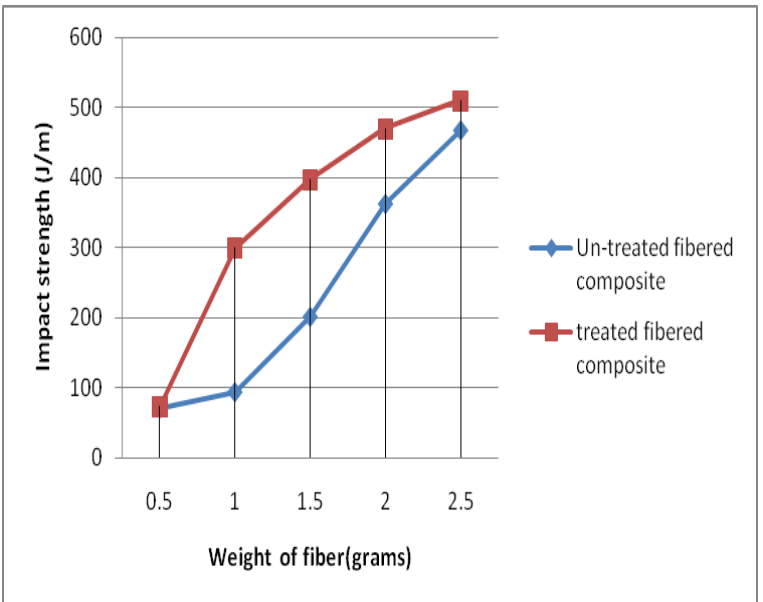

Figure 3.3: Variation of Impact energy of treated and untreated borassus flabellifer fiber /PVA composite with fiber loading.

\section{Conclusions}

By comparing the results of treated and untreated borassus flabellifer fiber /PVA composite with fiber loading it's clear that by chemical treatment one can increase the Impact strength of selected composite material. It's also observed that by varying the volume of fiber the Impact strength can also be increased up to maximum loading. It is clear that volume of fibre and treatment of fiber affects impact strength property of above said composite material

\section{References}

[1]. Eastham J. : Natural fibres for the automotive industry in 'Seminar of The Alternative Crops Technology Interaction Network, Manchester, UK’ 16, 142-146 (2001).

[2]. Han S. O., Defoort B., Drzal L. T., Askeland P. A.: Environmentally friendly biocomposites for automotive applications in '33 rd ISTC Conference, Seattle, USA’33, 1466-1477 (2001).

[3]. Marsh G.: Next step for automotive materials. Materials Today, 6, 36-43 (2003)

[4]. Chen Y., Chiparus O., Sun L., Negulescu I., Parikh D. V., Calamari T. A.: Natural fibers for automotive nonwoven composites. Journal of Industrial Textiles, 35, 47-62 (2005)

[5]. Gassan J., Bledzki A. K.: Possibilities for improving the mechanical properties of jute/epoxy composites by alkali treatment of fibres. Composites Science and Technology, 59, 1303-1309 (1999).

[6]. Gassan J., Bledzki A. K.: Effect of cyclic moisture absorption desorption on the mechanical properties of silanized jute-epoxy composites. Polymer Composites, 20, 604-611 (1999).

[7]. Gassan J., Gutowski V. S.: Effects of corona discharge and UV treatment on the properties of jute-fibre epoxy composites Composites Science and Technology, 60, 2857-2863 (2000).

[8]. Wei-ming Wang; Zai-sheng Cai; jian-yong Yu: Study on Chemical Modification Process of jute. Journal of Engineering fibers and fabrics Volume 3, Issue 2, 2008

[9]. Mohd Zuhri Mohamed Yusoff; Mohd Sapuan Salit; Napsiah Ismail; Riza Wirawan: Mechanical Properties of short random oil palm fiber reinforced epoxy composites. Sains Malaysiana 39(1)(2010): 87-92.

[10]. Morsyleide F. Rosa, Bor-sen Chiou, Eliton S. Medeiros: Effect of fiber treatments on tensile and thermal properties of starch/ethylene vinyl alcohol copolymers/coir biocomposites: Bioresource Technology 100 (2009) 5196-5202.

[11]. Beckerman G.W., Pickering, K.L., and foreman. N.J.: The Processing, Production and Improvement of hemp fibre reinforced polypropylene composite materials: proceedings of SPPM, 25-27 feb.2004. pp 257-265.

[12]. Dieu. T.V., Phai L.T.,Ngoc P.M.: Study on preparation of polymer composites based on polypropylene reinforced by jute fibers: JSME International journal, Series A: Solid mechanics \& Material engineering, Vol. 47, No.4, pp 547-550. 